\title{
Erbium-YAG laser therapy - analysis of more than 1,200 treatments
}

\author{
Uwe Wollina* \\ Department of Dermatology and Allergology, Academic Teaching Hospital Dresden-Friedrichstadt, 01309 Dresden, Germany
}

\begin{abstract}
Background: Ablative laser treatment is widely used in dermatology. Different laser types are available. In contrast to that, the medical publication on erbium-YAG laser in dermatology often include small samples only.

Objective: We want to demonstrate the versatility of classical erbium-YAG laser for medical conditions in dermatology in a single-center study.

Materials and methods: This is a retrospective analysis of patients treated between 2003 and 2011 at our department for benign, premalignant and malignant disorders. Laser treatment was realized with a $2940 \mathrm{~nm}$ MCL 29 Dermablate erbium-YAG laser.

Results: In total 1211 laser treatments have been performed. The age range of patients was between 8 years and 89 years. In $91 \%$ of treatments either no anesthesia or only topical prilocaine/ lidocaine ointment was necessary. Major indication for erbium-YAG laser treatment were hard to treat verrucae vulgares of hands and feet and other virus-induced lesions. The second largest disease group consisted of benign tumors with seborrheic keratosis on the lead. In most cases a single laser session was effective to remove the lesions completely. Adverse effects were rarely seen, such as pigment changes. Scars were commonly treated but they needed several laser sessions to obtain a $>50 \%$ improvement. Laser treatment for scars should be combined with other treatment modalities for better results. Premalignant lesions are an important indication. The complete clearance rate was high. In chronic actinic cheilitis we obtained $100 \%$ complete and stable clearance. Smaller superficial cutaneous metastases can be treated by laser in a palliative setting with minor morbidity and good local control.
\end{abstract}

Conclusion: Erbium-YAG is a versatile laser, a "working horse" for common cutaneous disorder. The treatment is comfortable for the patients with minor downtime, limited pain and mostly excellent outcome.

\section{Introduction}

The erbium-doped yttrium aluminium garnet (erbium-YAG) laser is a solid-state crystal laser. The laser light of 2,940 $\mathrm{nm}$ is strongly absorbed by water. This prevents laser cutting of skin and extensive scarring. Often either no anesthesia is needed or only topical anesthetic ointment.

The pulsed 2,940 $\mathrm{nm}$ erbium-YAG laser is a precise ablative tool. Cavity expansion, collapse and associated acoustic transients are responsible for photoacoustic vaporization followed by phase explosion and material ejection [1]. Erbium-YAG laser produces a measureable skin contraction after superficial ablation of between $5 \%$ and $14 \%$, a feature that is of interest in not only in esthetic surgery [2]. Collagen injury is less than with conventional $\mathrm{CO}_{2}$ laser and tissue regeneration is faster [3].

In comparison to $\mathrm{CO}_{2}$, the erbium-YAG led to clean ablation craters and precise cuts with only minimal adjacent tissue damage followed by excellent healing without apparent scarring. Longer pulse duration will increase thermal damage. This laser type has also bactericidal effects but does not coagulate effectively [4].

Erbium-YAG laser has been the working horse in many dermatologic clinics for years before the age of fractional lasers and other technical modifications. Surprisingly, larger studies on erbiumYAG laser in dermatology are sparse.

\section{Material and methods}

We evaluated the indications and treatment modalities as well the outcome and adverse effects of pulsed erbium-YAG laser therapy 2003-2011 at our department. During that time we used the laser MCL 29 Dermablate (Asclepion Laser Technologies, Jena, Germany). We included medical treatments only.

The wavelength of this laser is $2,940 \mathrm{~nm}$. The size of focus varied between $1.6 \mathrm{~mm}, 3 \mathrm{~mm}$ and $5 \mathrm{~mm}$. In most cases we used a frequency of $8 \mathrm{~Hz}$. The fluence was tailored to the skin type and type of lesion. In about $86 \%$ of treatments the pulse energy was between 600 to $800 \mathrm{~mJ}$, resulting in fluences between 11.3 to $20 \mathrm{~J} / \mathrm{cm}^{2}$. Thicker hyperkeratotic lesions needed a pulse energy of $1200 \mathrm{~mJ}$.

Patients and staff had protective goggles during laser treatment. Disinfection was performed before laser treatment and thereafter with a solution containing $0.1 \%$ octenidine dihydrochloride and $2.0 \%$ phenoxyethanol (Octenisept; Schülke \& Mayr, Norderstedt, Germany) for facial and mucous lesions. Other body areas were disinfected by 72\% propan-2-ol (Cutasept F; Bode, Hamburg, Germany).

Anesthetic procedures were discussed with the patient before and

Correspondence to: Prof. Dr. Uwe Wollina, MD, Department of Dermatology and Allergology, Academic Teaching Hospital Dresden-Friedrichstadt, Friedrichstrasse 41, 01309 Dresden, Germany, E-mail: wollina-uw@khdf.de

Key words: benign skin tumors, Erbium-YAG laser, hyperpigmentation, premalignant skin diseases, scars

Received: March 01, 2016; Accepted: March 22, 2016; Published: March 25, 2016 
during treatment. We did a single shot with the laser and asked again, whether anesthesia is needed or not. An evacuator with filters was used during the procedure to remove the plume.

Post-laser recommendations included sun-protection, avoidance of tanning salon, use of moisturizes and scar ointments (if needed) [5].

\section{Results}

A total of 1211 treatments was analyzed, i.e. 699 treatments for males and 512 treatments for females. The age of patients ranged from 8 to 89 years (mean $58 \pm 26$ years). Caucasians represented $97 \%$ of patients with predominant Fitzpatrick skin type II. Of all treatments $25 \%$ did not need any type of anesthesia (mainly superficial, thinner, smaller and limited lesions, but also seborrheic keratosis on the trunk). In $66 \%$ a topical anesthetic ointment (EMLA 5\% cream, AstraZeneca, Södertälje, Sweden) was used. In $9 \%$ prilocaine $1 \%$ solution (Xylonest $1 \%$; AstraZeneca) was injected intracutaneous.

The top 12 indication for erbium-YAG laser treatment in our department is shown in Figure 1.

The important indication was common warts - periungual, subungual, and plantar warts $(n=388)$. In patients with extensive involvement several sessions were needed due to pain and bleeding at the end of laser treatment (up to 12 , mean $4 \pm 7$ ). The complete clearance rate was $68 \%$ for plantar warts, $78 \%$ for periungual warts and $76 \%$ for subungual warts. Due to the infectious nature relapses have seen in particular in plantar warts (relapse rate: 17.8\%). Other viral infectious disorders treated were smaller condyloma acuminata $(n=25)$ and mollusca contagiosa $(n=20)$, which needed only 1 laser session.

In case of seborrheic keratosis $(n=240), 83 \%$ of patients presented with multiple lesions. In these patients two to three sessions were needed to remove all lesions. Healing without scars or pigment changes was achieved in 99\%. Closely related to seborrheic keratosis is papulosis nigra - a special subtype with multiple hyperpigmented small papules in darker Fitzpatrick skin types. We treated 10 patients with excellent results in all but one were a prolonged postinflammatory hyperpigmentation was seen.

Achrochordons of neck and axillaries $(\mathrm{n}=32)$ were also treated. For larger achrochordons bipolar forceps was used for hemostasis, since the erbium-YAG laser does not coagulate.

Fibrous papule of the nose is a disfiguring benign disorder. Only a single treatment was necessary to gain a complete response with

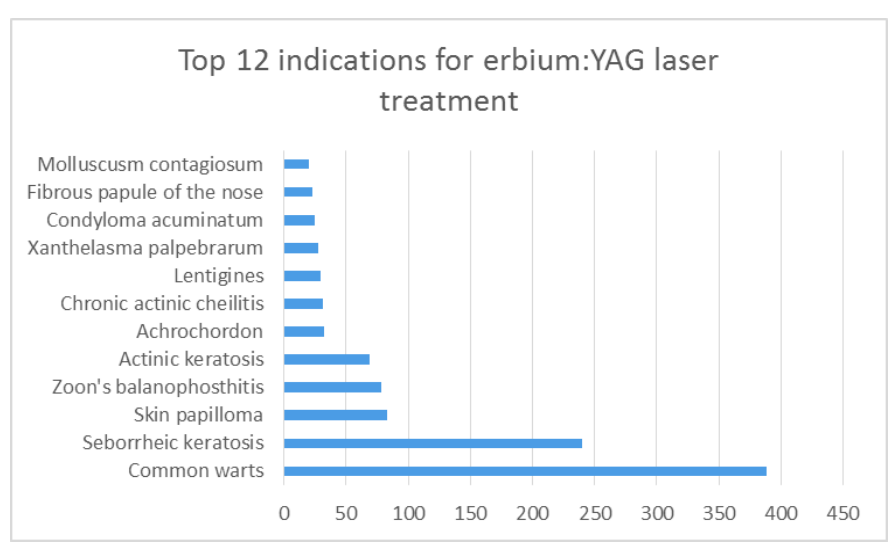

Figure 1. The top 12 indications for erbium-YAG laser therapy in the present study. The bottom line shows the number of patients treated.

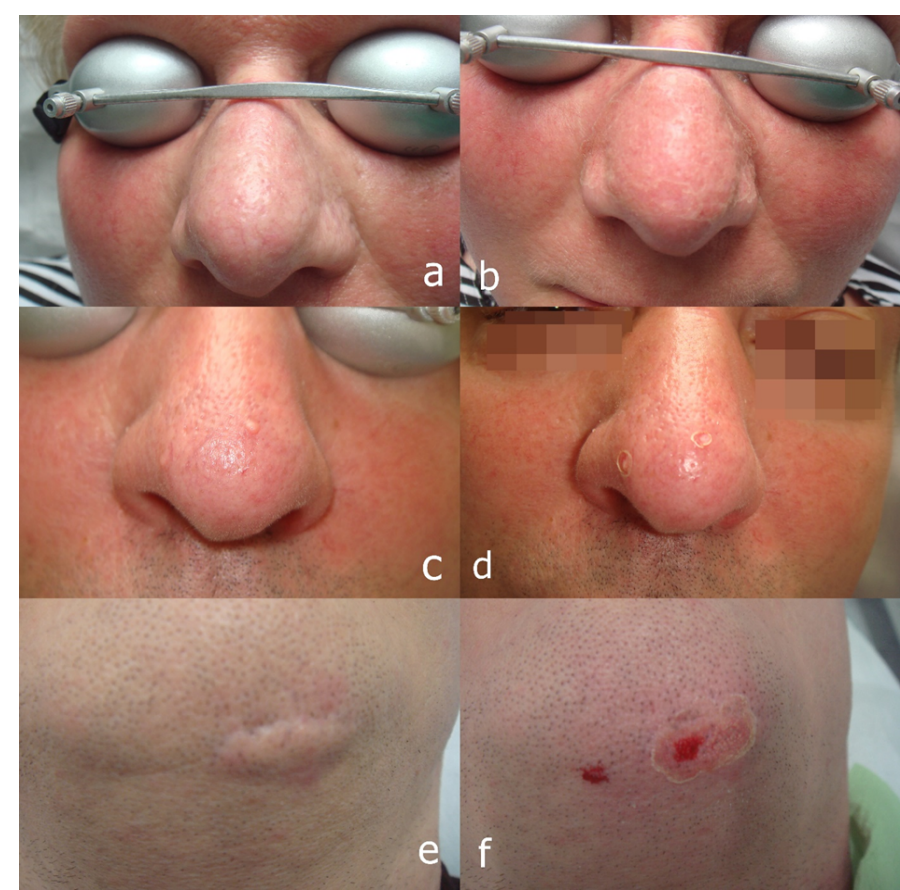

Figure 2. Erbium-YAG laser treatment of facial lesions. Sebaceous gland hyperplasia (a) before and (b) immediately after laser. Fibrous papules of the nose (c) before and (d) immediately after laser. Hypertrophic scar (e) before and (f) after laser treatment.

excellent esthetic outcome $(n=10)$. We have seen no scarring or pigment changes at all.

Papillomatous melanocytic nevi $(n=83)$ were treated by erbiumYAG laser mainly for esthetic reasons. In all cases dermoscopy was performed before to exclude doubtful lesions. Atypical melanocytic lesions were referred to dermato-surgery. Outcome was favorable in almost all patients. Slight hypopigmentation was seen in a single male patient who used to attend a tanning salon despite our recommendation of sun/ ultraviolet light protection. In about $10 \%$ of cases a second treatment of the lesions was necessary due to partial relapse. Rare indications were osteoma cutis $(n=3)$, milia $(n=5)$, epidermal nevus $(\mathrm{n}=3)$, nasal granuloma, sebaceous nevus and steatocystoma multiplex $(\mathrm{n}=1$ each) (Figure 2).

Hyperpigmentation can also be treated by erbium-YAG laser. We recommend a dermoscopy investigation in all hyperpigmented lesions for safety reasons. In our case the most common indication was lentigines $(n=29)$. Here a slight erythematous post-laser response is often seen. Sun- / ultraviolet light protection is warranted. All lesions healed without leaving scar or pigmentary changes. Postinflammatory hyperpigmentations $(n=12)$ need more caution to avoid a relapse. A combination with oral vitamin $\mathrm{C}$ and tocopherol plus sun protection factor 50 ointment were recommended. Labial melanotic macules can be treated safely without leaving textural or pigmentary changes. In case of traumatic tattoos $(\mathrm{n}=7)$ several treatments are necessary to achieve a good cosmesis.

Benign eyelid dermatoses are an indication for erbium-YAG laser therapy. The most common diagnosis was xanthelasma palpebrarum $(n=28)$, in several cases relapsed after lid surgery. In 25 of 28 patients only on laser session was needed. Bleeding during the procedure may prevent the complete removal. Bipolar forceps was not used. Under these circumstances a second laser session was performed. No scarring or texture changes were noted after the procedure. 
Eyelid fibromas $(n=4)$ were removed in a single session with excellent results. Twenty-four patients were treated for syringomas of the eyelids. Between one and three sessions were necessary to remove $>80 \%$ of these tiny eccrine tumors. A relapse may occur during hot summer.

Hypertrophic scars $(n=25)$ and atrophic acne scars $(n=13)$ can be improved by erbium-YAG laser treatment (Figure $2 \mathrm{c}$ and $2 \mathrm{~d}$ ). In both indications a number of treatments is necessary. For hypertrophic scars, laser is an adjuvant to other measures such as topical corticosteroids, silicon gels or sheets and compression therapy. In case of acne scars acute inflammatory lesions increase the risk of pigment changes. Lasers should not be used during retinoid therapy. The realistic goal of such treatment is not a cure but an improvement $>50 \%$.

Balanophosthitis plasmacelluaris (Zoon) - a benign chronic inflammatory disease genital mucosa - is an important indication in our practice. We see the laser in males as an alternative to circumcision with less downtime and preservation of the prepuce. Diagnosis needs histologic confirmation to exclude early penile cancer. We have performed erbium-YAG laser therapy in 78 patients. We used a $3 \mathrm{~mm}$ or $5 \mathrm{~mm}$ focus depending on the size of the erythematous lesions. In most cases a pulse energy of $600 \mathrm{~mJ}$ was sufficient. Bleeding was noted in 5 cases (all on anticoagulants) leading to more than one laser treatment in these patients. All other patients were sufficiently treated by a single laser session with 2 to 3 passes. The response rate was 100\% (Figure 3).

Premalignant disorders such as actinic keratosis $(n=69)$, chronic actinic cheilitis $(n=31)$, and Bowen's disease $(n=2)$ were removed by erbium-YAG laser. The complete response rate after a single laser session was $98.6 \%$ for actinic keratosis, $100 \%$ for cheilitis and $100 \%$ for Bowen's disease. The whole lower lip was treated by two to three passes with a $5 \mathrm{~mm}$ focus and pulse energy of $800 \mathrm{~mJ}$.

Erbium-YAG laser can be used for malignant tumors in a palliative setting. Multiple small cutaneous metastases of less than $4 \mathrm{~mm}$ diameter of breast cancer $(n=1)$ or malignant melanoma $(n=2)$ were treated with a $3 \mathrm{~mm}$ focus and a pulse energy of $1200 \mathrm{~mJ}$. The lesions healed within two weeks without leaving a scar. We have also treated a female patient with multiple tiny naevoid basal cell carcinomas of the face and trunk (Gorlin-Goltz syndrome) with the laser ( $3 \mathrm{~mm}$ focus, pulse energy $800 \mathrm{~mJ})$.

Several rare diagnoses have also been subjected to erbium-YAG laser such as actinic porokeratosis, dyskeratosis follicularis (Darier) or benign chronic familial pemphigus (Hailey-Hailey) not responding to other treatments. Here the outcome was mixed with some areas getting better and others that did not respond.

\section{Discussion}

The erbium-YAG laser is an ablative laser that can be used safely

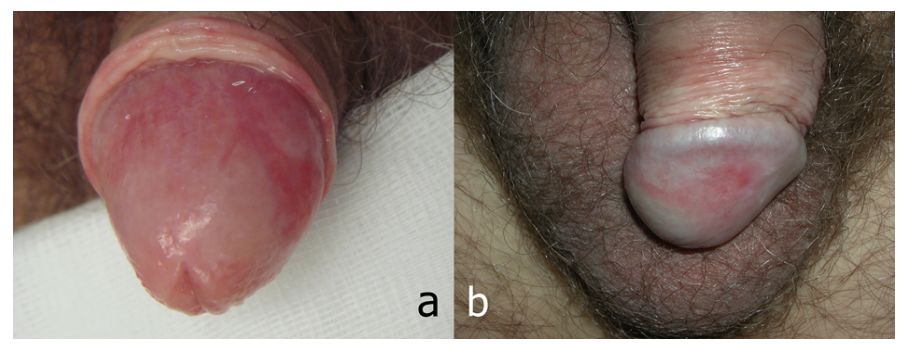

Figure 3. Noncicatrical balanoposthitis Zoon (a) before and (b) 4 weeks after laser treatment. for removal of benign, pre-malignant and malignant skin lesions. The major limitation of the erbium-YAG laser is its weakness on hemostasis. On the other hand it offers a precise ablation with limited thermal damage of the neighboring tissue $[4,6]$.

An important indication in our hand was the treatment of common warts especially on hands and feet. Here the erbium-YAG laser offers an advantage for patients and staff, since the plume is free of human papilloma virus DNA in contrast to $\mathrm{CO}_{2}$ laser $[7,8]$.

Erbium-YAG laser treatment of 121 plantar warts resulted in fast healing without hypertrophic scars and a low recurrence rate of $<6 \%$ after 12 months [9]. We demonstrated earlier in an open trial that common warts in hard to treat areas, i.e. peri- and subungual or plantar, respond to erbium-YAG laser in $72.5 \%$ [10]. This is also the success rate we have seen in the present analysis of almost 400 procedures in 312 patients. Larger plantar warts needed to be treated more often, more aggressive. Since formation of hypertrophic scars has been reported in patients treated with lasers for common warts too aggressive laser therapy should be avoided [11].

Seborrheic keratosis are common in patients above the age of 50 years. Although they do not represent any severe health risk the appearance of multiple lesions may be annoying for the patient. Sometimes pruritus and superficial bleeding due to mechanical irritation are associated. Often curettage or cryotherapy is used, both with comparable efficacy but slightly different cosmesis due to hypopigmentation after cryotherapy [12]. In a recent randomized trial, erbium-YAG laser was more effective than cryotherapy with a better esthetical outcome [13]. This is also our impression, although no comparative trial had been performed by us. Patients who had curettage before reported less pain after erbium-laser.

Patients with hyperpigmented lesions such as actinic lentigines or labial melanotic macules benefit a lot from erbium-YAG laser. In most patients a single treatment completely removes the spots and healing is fast. With many other treatments such as cryotherapy or other lasers post-inflammatory hyperpigmentation is a challenge [14]. However, post-laser treatment needs sun-/ultraviolet light-protection and a moisturizer [10]. In case of posttraumatic tattoos early treatment provides better results $[15,16]$.

Periocular lesions are common. Fibromas, xanthelasmas, papulosis nigra or syringomas can be found here causing negative effects on esthetic perception. Such lesions can be removed with excellent outcome by the erbium-YAG laser [17-20]. Only, in case of bleeding lesions, a second session will be necessary. We have not used bipolar forceps in these patients to avoid any risk of scarring.

Treatment of hypertrophic scars needs a complex approach with skin care, silicon dressings, corticosteroid injections etc. Ablative laser therapy can serve as adjuvant procedure [21,22]. Atrophic scars improve after several sessions with the erbium-YAG laser. This is considered to be a safe method for scar correction [23].

Erbium-YAG lasers have been among the first effective lasers in the treatment of atrophic acne scars [22]. In a study from Turkey on 128 patients with acne scars the investigators observed improvement of skin texture, scars and pigmentation [24]. We noted a good response after several session but no complete cure of course. It is important to communicate the partial improvement as the goal of laser treatment to the patients.

There is a wide range of benign tumors, cysts or hyperkeratotic 
disorders that have been successfully treated or at least alleviated by erbium-YAG laser application such as nevus sebaceous, actinic porokeratosis, osteoma cutis or angiokeratoma [25-29].

Balanophosthitis plasmacelluaris (Zoon) is a benign disease of external genitals more often seen in elderly males than females. Biopsy is necessary to exclude premalignant and malignant differential diagnoses. Topical therapies are often prescribed with very limited benefit for the patient. In males circumcision is a surgical option [30]. An alternative to surgery with less downtime and preservation of the prepuce is ablative erbium-YAG laser therapy. We have performed almost 80 treatments with the erbium-YAG laser without any scarring. Erbium-YAG laser therapy leads to a stable remission in patients with Zoon's balanophostitis [31,32]. Late recurrences after 12 months are possible (in 3 patients), but the lesions developed only in previously untreated parts of the glance or the prepuce.

The erbium-YAG laser is a versatile tool to treat premalignant conditions of skin and lips. Actinic keratosis showed a complete response after a single erbium-YAG laser session in almost $90 \%$ in an earlier open trial [10].

Chronic actinic cheilitis is an obligate precancerous disease. The classical surgical option is vermillectomy. Patients who underwent a full lip erbium-YAG laser treatment for chronic actinic cheilitis were very satisfied. In a retrospective study $92.2 \%$ reported an improvement in cosmetic appearance. But even more important, almost $85 \%$ remained completely disease free during follow-up of mean 65.7 months. $93.5 \%$ of patients were satisfied with the laser treatment [33].

Palliative treatment of small cutaneous metastases is helpful to control the disease without morbidity and negative impact of the quality of health of such patients. Larger and deeper seated metastases will benefit more from $\mathrm{CO}_{2}$ laser $[34,35]$.

In conclusion, erbium-YAG laser is a versatile tool in dermatosurgery. The treatment offers minor pain and low risk of adverse effects for the patients. In many cases the outcome is excellent. Although laser technology makes progress year after year the simple and reliable technique of erbium-YAG offers a good and serious option for the dermatologist.

\section{References}

1. Loertscher H, Shi WQ, Grundfest WS (1992) Tissue ablation through water with erbium:YAG lasers. IEEE Trans Biomed Eng 39: 86-88. [Crossref]

2. Hughes PS (1998) Skin contraction following erbium:YAG laser resurfacing. Dermatol Surg 24: 109-111. [Crossref]

3. Utley DS, Koch RJ, Egbert BM (1999) Histologic analysis of the thermal effect on epidermal and dermal structures following treatment with the superpulsed $\mathrm{CO}_{2}$ laser and the erbium: YAG laser: an in vivo study. Lasers Surg Med 24: 93-102. [Crossref]

4. Kaufmann R, Hibst R (1990) Pulsed 2.94-microns erbium-YAG laser skin ablation-experimental results and first clinical application. Clin Exp Dermatol 15: 389-393. [Crossref]

5. Wollina U (2010) Pre- and post-laser treatment in cosmetic dermatology. Eur Dermatol 5: 47 .

6. Khatri KA (2003) Ablation of cutaneous lesions using an erbium:YAG laser. $J$ Cosmet Laser Ther 5: 150-153. [Crossref]

7. Hughes PS, Hughes AP (1998) Absence of human papillomavirus DNA in the plume of erbium:YAG laser-treated warts. J Am Acad Dermatol 38: 426-428. [Crossref]

8. Kashima HK, Kessis T, Mounts P, Shah K (1991) Polymerase chain reaction identification of human papillomavirus DNA in $\mathrm{CO}_{2}$ laser plume from recurrent respiratory papillomatosis. Otolaryngol Head Neck Surg 104: 191-195. [Crossref]

9. Trelles MA, Allones I, Mayo E (2006) Er:YAG laser ablation of plantar verrucae with red LED therapy-assisted healing. Photomed Laser Surg 24: 494-498. [Crossref]

10. Wollina U, Konrad H, Karamfilov T (2001) Treatment of common warts and actinic keratoses by Er:YAG laser. J Cutan Laser Ther 3: 63-66. [Crossref]

11. Ozluer SM, Chuen BY, Barlow RJ, Markey AC (2001) Hypertrophic scar formation following carbon dioxide laser ablation of plantar warts in cyclosporin-treated patients. Br J Dermatol 145: 1005-1007. [Crossref]

12. Wood LD, Stucki JK, Hollenbeak CS, Miller JJ (2013) Effectiveness of cryosurgery vs curettage in the treatment of seborrheic keratoses. JAMA Dermatol 149: 108-109. [Crossref]

13. Gurel MS, Aral BB (2015) Effectiveness of erbium:YAG laser and cryosurgery in seborrheic keratoses: Randomized, prospective intraindividual comparison study. $J$ Dermatolog Treat. 26: 477-480. [Crossref]

14. Hexsel D, Hexsel C, Porto MD, Siega C (2015) Triple combination as adjuvant to cryotherapy in the treatment of solar lentigines: investigator-blinded, randomized clinical trial. J Eur Acad Dermatol Venereol 29: 128-133. [Crossref]

15. Kunzi-Rapp K, Krähn GM, Wortmann S, Peter RU (2001) Early treatment of traumatic tattoo by erbium-YAG laser. Br J Dermatol 144: 219-221. [Crossref]

16. Cambier B, Rogge F (2006) Traumatic tattoo: use of the variable pulsed erbium:YAG laser. Photomed Laser Surg 24: 605-609. [Crossref]

17. Riedel F, Windberger J, Stein E, Hörmann K (1998) [Treatment of peri-ocular skin lesions with the erbium:YAG laser]. Ophthalmologe 95: 771-775. [Crossref]

18. Borelli C, Kaudewitz P (2001) Xanthelasma palpebrarum: treatment with the erbium:YAG laser. Lasers Surg Med 29: 260-264. [Crossref]

19. Mannino G, Papale A, De Bella F, Mollo R, Morgia P, et al. (2001) Use of Erbium:YAG laser in the treatment of palpebral xanthelasmas. Ophthalmic Surg Lasers 32: 129-133. [Crossref]

20. Güngör S, Canat D, Gökdemir G (2014) Erbium: YAG laser ablation versus $70 \%$ trichloroacetic acid application in the treatment of xanthelasma palpebrarum. $J$ Dermatolog Treat 25: 290-293. [Crossref]

21. Tredget EE, Levi B, Donelan MB (2014) Biology and principles of scar managemen and burn reconstruction. Surg Clin North Am 94: 793-815. [Crossref]

22. Khatri KA, Mahoney DL, McCartney MJ (2011) Laser scar revision: A review. $J$ Cosmet Laser Ther 13: 54-62. [Crossref]

23. Mezzana P, Sonnino M, Madonna Terracina FS, Valeriani M (2001) Treatment of atrophic scars with Er:YAG laser: our experience. Acta Chir Plast 43: 26-28. [Crossref]

24. Kutlubay Z, Gokdemir G (2010) Treatment of atrophic facial acne scars with the Er:YAG laser: a Turkish experience. J Cosmet Laser Ther 12: 65-72. [Crossref]

25. Armenores P, James CL, Walker PC, Huilgol SC (2010) Treatment of actinic cheilitis with the Er:YAG laser. J Am Acad Dermatol 63: 642-646. [Crossref]

26. Caers SJ, Van der Geer S, Beverdam EG, Krekels GA, Ostertag JU (2008) Successful treatment of nevus comedonicus with the use of the Erbium Yag laser. J Eur Acad Dermatol Venereol 22: 375-377. [Crossref]

27. Rosenblum J, Roenigk HH Jr (2013) Erbium laser for the treatment of disseminated superficial actinic porokeratosis: a case report. Dermatol Surg 39: 1543-1545. [Crossref]

28. Ochsendorf FR, Kaufmann R (1999) Erbium: YAG laser ablation of osteoma cutis: modifications of the approach. Arch Dermatol 135: 1416. [Crossref]

29. Konrad H, Karamfilov T, Wollina U (2001) Intracutaneous botulinum toxin A versus ablative therapy of Hailey-Hailey disease--a case report. J Cosmet Laser Ther 3: 181184. [Crossref]

30. Bechara FG, Jansen T, Wilmert M, Altmeyer P, Hoffmann K (2004) Angiokeratoma Fordyce of the glans penis: combined treatment with erbium: YAG and $532 \mathrm{~nm}$ KTP (frequency doubled neodynium: YAG) laser. J Dermatol 31: 943-945. [Crossref]

31. Kumar B, Narang T, Dass Radotra B, Gupta S (2006) Plasma cell balanitis clinicopathologic study of 112 cases and treatment modalities. J Cutan Med Surg 10: 11-15. [Crossref]

32. Wollina U (2010) Ablative erbium:YAG laser treatment of idiopathic chronic inflammatory non-cicatricial balanoposthitis (Zoon's disease)--a series of 20 patients with long-term outcome. J Cosmet Laser Ther 12: 120-123. [Crossref]

33. Wollina U (2006) Erbium-YAG-laser treatment of balanoposthitis chronica circumscripta benigna plasmacellularis Zoon. Med Laser Appl 21: 23-26.

34. van Jarwaarde JA, Wessels R, Nieweg OE, Wouters MW, van der Hage JA (2015) CO2 
Wollina U (2016) Erbium-YAG laser therapy - analysis of more than 1,200 treatments

laser treatment for regional cutaneous malignant melanoma metastases. Dermatol Surg 41: 78-82. [Crossref]
35. John HE, Mahaffey PJ (2014) Laser ablation and cryotherapy of melanoma metastases. J Surg Oncol 109: 296-300. [Crossref]

Copyright: $\left({ }_{2} 2016\right.$ Wollina U. This is an open-access article distributed under the terms of the Creative Commons Attribution License, which permits unrestricted use, distribution, and reproduction in any medium, provided the original author and source are credited. 